\title{
Fermentative Production of Mycelial Chitosan from Zygomycetes: Media Optimization and Physico-Chemical Characterization
}

\author{
Pradnya N. Vaingankar*, Archana R. Juvekar \\ Department of Pharmaceutical Science and Technology, Institute of Chemical Technology, Mumbai, India \\ Email: "pradnya_v17@yahoo.com
}

Received 8 August 2014; revised 16 September 2014; accepted 3 October 2014

Copyright (C) 2014 by authors and Scientific Research Publishing Inc.

This work is licensed under the Creative Commons Attribution International License (CC BY).

http://creativecommons.org/licenses/by/4.0/

cC) (†) Open Access

\begin{abstract}
The present study focused on production of mycelial chitosan from fungal mycelium by submerged fermentation with ecologically more balanced process. Different fungal strains were screened and Absidia butleri NCIM 977 was found to produce the highest mycelial chitosan. The one-factor-at-a-time method was adopted to investigate the effect of batch time, environmental factors (i.e. initial $\mathrm{pH}$ and temperature) and medium components (i.e. carbon and nitrogen) on the yield of mycelial chitosan. Among these variables, the optimal condition to increase in yield of mycelial chitosan was found to be batch time $(72 \mathrm{~h}), \mathrm{pH}(5.5)$, temperature $\left(30^{\circ} \mathrm{C}\right)$, carbon source (glucose) and nitrogen source (tryptone and yeast extract). Subsequently, a three-level BoxBehnken factorial design was employed combining with response surface methodology (RSM) to maximise yield of mycelial chitosan by determining optimal concentrations and investigating the interactive effects of the most significant media components (i.e. carbon and nitrogen sources). The optimum value of parameters obtained through RSM was glucose $(1.58 \%)$, tryptone $(1.61 \%)$ and yeast extract $(1.11 \%)$. There was an increase in mycelial chitosan yield after media optimization by one-factor-at-a-time and statistical analysis from $683 \mathrm{mg} / \mathrm{L}$ to $1 \mathrm{~g} / \mathrm{L}$. Mycelial chitosan was characterized for total glucosamine content $(\mathbf{8 0 . 6 8 \%})$, degree of deacetylation (DD) $(\mathbf{7 9 . 8 9 \% )}$, molecular weight $\left(8.07 \times 10^{4} \mathrm{Da}\right)$ and, viscosity $(73.22 \mathrm{ml} / \mathrm{g})$. The results of this study demonstrated that fungi are promising alternative sources of chitosan with high DD and high purity.
\end{abstract}

\section{Keywords}

Mycelial Chitosan, Submerged-State Fermentation, Response Surface Methodology, Box-Behnken

\footnotetext{
"Corresponding author.
}

How to cite this paper: Vaingankar, P.N. and Juvekar, A.R. (2014) Fermentative Production of Mycelial Chitosan from Zygomycetes: Media Optimization and Physico-Chemical Characterization. Advances in Bioscience and Biotechnology, 5, 940956. http://dx.doi.org/10.4236/abb.2014.512108 


\section{Design, Characterization}

\section{Introduction}

Chitosan is a natural amino polysaccharide comprising copolymers of D-glucosamine (GlcN) and N-acetylD-glucosamine (GlcNAc), and is a deacetylated derivative of chitin-the second most abundant natural polymer after cellulose [1]. It is polycationic, nontoxic, biodegradable as well as antimicrobial and has been reported to have numerous applications especially in food, pharmaceutics and cosmetics [2]-[4].

Commercially available chitosan produced by chemical deacetylation of chitin has several disadvantages as isolation of chitin from crustacean shells and its conversion to chitosan requires strong alkali treatment, high temperature, and a long processing time, which make this process costly [5]. Further, multiple chemical treatments cause an increase in the level of environmental pollution [6].

Recent advances in fermentation technology addressed that many of these problems can be overcome by culturing chitosan-producing fungi, particularly Zygomycetes species, which are known to contain chitosan as natural cell wall component [7]-[10].

Chitosan in cell walls produced through enzymatic deacetylation of chitin chain through the action of $N$-deacetylation is a common step in the modification of sugar chains [11]. Mycelial chitosan offers significant advantages; the most important is like where crustacean waste supplies are limited by seasons and sites of fishing industry; fungal mycelium can be obtained by convenient fermentation process with organisms that can be readily cultured on cheap nutrients and the cell wall material can be recovered by simple chemical procedures. Fungal mycelia have lower level of inorganic materials compared to crustacean wastes, and thus no demineralization treatment is required during the processing. Furthermore, the mycelial chitosan is free of heavy metal contents such as nickel and copper [12] [13]. Crustacean chitosan may vary in the physico-chemical properties, while mycelial chitosan has relatively consistent properties [12]-[16].

Insight of the above advantages, the objective of present work is mainly focused to screen different fungal strains and to optimize culture conditions using one-factor-at-a-time and statistical analysis by response surface methodology (RSM) based on the Box-Behnken design for the highest production of mycelial chitosan by submerged fermentation. RSM was employed to build models, to evaluate the effective factors and their interaction and to select optimum conditions, with a minimum number of experiments. Furthermore, characterization of physical properties of produced mycelial chitosan was investigated.

\section{Materials and Method}

\subsection{Micro-Organism and Its Maintenance}

Five different strains of Zygomycetes, namely, Absidia blakesleeana NCIM 889, Absidia butleri NCIM 977, Cunninghamella blakesleeana NCIM 687, Cunninghamella echinulata NCIM 691 and Rhizopus oryaze NCIM 1009 were purchased from National Collection of Industrial Microorganism (NCIM) Pune, India. For the screening, all the five strains were grown and maintained on potato dextrose agar (PDA) slants, grown at $30^{\circ} \mathrm{C}$ for 10 days and stored at $4^{\circ} \mathrm{C}$ and subcultured on a monthly basis. The chemicals and media components utilized in the present study were procured from Hi-Media (Mumbai, India). Concentrated NaOH solution was commercial grade and all chemicals were of analytical grade. Standards of chitosan were obtained from Sigma Chemical Co. (St. Louis, MO, USA).

\subsection{Medium and Culture Conditions}

The inoculum was prepared in Erlenmeyer flasks $(250 \mathrm{ml})$ containing $100 \mathrm{ml}$ of potato dextrose broth, inoculated with spore suspension $\left(1.8 \times 10^{8}\right.$ spores $\left./ \mathrm{ml}\right)$ and incubated at $30^{\circ} \mathrm{C}$ for $16 \mathrm{~h}$ on a rotatory shaker $(180 \mathrm{rpm})$. A $7.5 \%(\mathrm{v} / \mathrm{v})$ of sixteen hr old inoculums was added aseptically to the $500 \mathrm{ml}$ Erlenmeyer flasks, each containing $200 \mathrm{ml}$ of the sterile production media of glucose $2 \%$, peptone $1 \%$, yeast extract $0.1 \%$, $\left(\mathrm{NH}_{4}\right)_{2} \mathrm{SO}_{4} 0.5 \%$, $\mathrm{K}_{2} \mathrm{HPO}_{4} 0.1 \%, \mathrm{NaCl} 0.1 \%, \mathrm{CaCl}_{2} \mathrm{H}_{2} \mathrm{O} 0.01 \%, \mathrm{MgSO}_{4} \cdot 7 \mathrm{H}_{2} \mathrm{O} 0.05 \%$ [12]. The $\mathrm{pH}$ of production media was adjusted to 4.5 using hydrochloric acid. All inoculated flasks were kept on a rotary shaker at $30^{\circ} \mathrm{C} \pm 2{ }^{\circ} \mathrm{C}$ and 180 
rpm. Various strains belonging to Zygomycetes species were screened for production of mycelial chitosan. The concentration of various carbon and nitrogen sources and culture conditions varied according to the experimental design described below. Unless otherwise stated, the cultivation was carried out using $500 \mathrm{ml}$ Erlenmeyer flasks on a $180 \mathrm{rpm}$ shaker at $30^{\circ} \mathrm{C} \pm 2^{\circ} \mathrm{C}$. All procedures were performed in triplicate.

\subsection{Optimization of Physical Parameters Using One-Factor-at-a-Time Approach}

To determine the optimum batch time for mycelial chitosan production, its production was carried out under the defined conditions, for different time periods ranging from 12 to $96 \mathrm{~h}$. In order to investigate effect of initial $\mathrm{pH}$ of production media, fermentation runs were carried at initial $\mathrm{pH}$ varying from 3 to 6 . The $\mathrm{pH}$ was adjusted using $0.1 \mathrm{~N}$ hydrochloric acid or $0.1 \mathrm{~N}$ sodium hydroxide. The effect of temperature on biomass and yield of mycelial chitosan was studied by incubating the production medium at varying temperature from $25^{\circ} \mathrm{C}$ to $30^{\circ} \mathrm{C}$. In all three parameters after incubation, biomass was harvested, filtered through Whatman filter paper no. 1, washed with distilled water and dried them at $60^{\circ} \mathrm{C}$ to a constant weight to determine the cell dry weight.

\subsection{Effect of Different Carbon Sources on Mycelial Chitosan Yield}

Several carbon sources were used to study the effect on mycelial chitosan production. To study the effect of various carbon sources on chitosan production, in the production medium, D (+) glucose was substituted with eight different carbon sources. All the carbon sources were used at $2 \%(w / v)$ concentration. Rests of the physicochemical parameters were constant.

\subsection{Effect of Different Nitrogen Sources on Mycelial Chitosan Yield}

To evaluate the effect of different nitrogen sources on mycelial chitosan production, combination of peptone (1\% $\mathrm{w} / \mathrm{v})$, yeast extract $(0.1 \% \mathrm{w} / \mathrm{v})$ and ammonium sulphate $(0.5 \% \mathrm{w} / \mathrm{v})$ was replaced with different nitrogenous sources (both organic and inorganic) with concentration of $1.6 \% \mathrm{w} / \mathrm{v}$. Mycelial chitosan yield and dry cell weight (DCW) were determined and rest of the physicochemical parameters were constant.

\subsection{Experimental Design and Data Analysis}

The most influential factors for mycelial chitosan production found by "one-factor-at-a-time" approach were further optimized with statistical approach. To describe the level of the significant parameters, interaction between variables, which influence the yield of mycelial chitosan and, the nature of the response surface in the optimum region, a Box-Behnken design [17], and the response surface methodology was performed.

\subsection{Box-Behnken Design}

In this study, the experimental plan consisted of 17 trials and the independent variables are studied at three different levels, low $(-1)$, medium $(0)$ and high $(+1)$. The variables and their coded levels used for the study are shown in Table 1. All the experiments were done in triplicate and the average of mycelial chitosan yield obtained was taken as the dependent variable or response $\left(Y_{C Y}\right)$. The second-order polynomial coefficients were calculated and analyzed using the Design Expert version 7.0.0 (STAT-EASE Inc., Minneapolis, MN, USA), statistical package.

The general form of the second degree polynomial Equation (1) is

$$
Y_{C Y}=\beta_{0}+\sum_{i=1}^{k} \beta_{i} X_{i}+\sum_{i=1}^{k} \beta_{i i} X_{i} X_{j}+\sum_{i} \sum_{i<j}^{k} \beta_{i j} X_{i} X_{j}
$$

where, $Y_{C Y}$ is the predicted response; $\beta_{0}$ a constant; $\beta_{i}$ the linear coefficient; $\beta_{i i}$ the squared coefficient; and $\beta_{i j}$ the cross-product coefficient, $k$ is number of factors, $x_{i}$ and $x_{j}$ the level of the independent variables, subscripts $i$ and $j$ takes values from 1 to the number of variables.

In the present study, three variables are involved and hence $\mathrm{n}$ takes the value 3 . Thus, by substituting the value 3 for $n$, and the coded variables for natural ones, Equation (1) becomes the following form: The yield of mycelial chitosan was taken as dependent variable or response $Y_{C Y}$, and a multiple regression analysis of the data was carried out for obtaining an empirical model that relates the response measured to the independent variables. 
Table 1. Experimental range, level and code of independent variables.

\begin{tabular}{cccccc}
\hline Independent variables $(\% \mathrm{w} / \mathrm{v})$ & Symbols & \multicolumn{3}{c}{ Coded values } \\
\cline { 3 - 5 } & Glucose & A & 1.5 & 2 & 2.5 \\
Tryptone & B & 1.1 & 1.6 & 2.1 \\
Yeast extract & C & 1.1 & 1.6 & 2.1 \\
\hline
\end{tabular}

\subsection{Statistical Analysis of Data}

The statistical and regression analyses of experimental data obtained from Box-Behnken design was done by using software Design Expert version 7.0.0 (STAT-EASE Inc., Minneapolis, MN, USA) to determine the significant differences $(\mathrm{p} \leq 0.05)$ in response under different conditions. Three-dimensional surface plots were constructed for visualization of interaction between significant variables and their optimal values. The goodness of fit of the model was evaluated by the coefficient of determination $\left(\mathrm{R}^{2}\right)$ and the analysis of variance (ANOVA) and its statistical significance was checked by an $F$ test quadratic polynomial equations were attained by holding one of the independent variances at a constant value and changing the level of the other variables.

\subsection{Extraction of Mycelial Chitosan}

The dried fungal cell mass was finely homogenized and subjected to alkali treatments to extract alkali soluble material like glucan and protein, present in fungal biomass. Dried mycelia homogenized dry cell mass were treated with $1 \mathrm{~N}$ sodium hydroxide solution (1:40, w/v) carried out by autoclaving biomass at $121^{\circ} \mathrm{C}$ for $20 \mathrm{~min}$. The alkali insoluble materials (AIM) were centrifuged (10,000 rpm, $15 \mathrm{~min}$ ), washed with distilled water, until it completely gets neutralized and further treated with $2 \%$ acetic acid (1:40, w/v) at $95^{\circ} \mathrm{C}$ for $6 \mathrm{~h}$, closely following the method of [18]. Through centrifugation, the supernatant, containing the chitosan, was isolated from the acid insoluble fraction. The mycelial chitosan was precipitated from supernatant by adjusting pH 10.0 with 2 M sodium hydroxide. The precipitate was centrifuged (10,000 rpm, $15 \mathrm{~min}$ ) and washed with distilled water to $\mathrm{pH} 7$, followed by $95 \%(\mathrm{v} / \mathrm{v})$ ethanol $(1: 20, \mathrm{w} / \mathrm{v})$ and acetone $(1: 20, \mathrm{w} / \mathrm{v})$, and dried at $60^{\circ} \mathrm{C}$ for $24 \mathrm{~h}$ and, weighed to calculate a mycelial chitosan yield. According to McGahren et al. [19] the alkali-insoluble precipitate obtained after suitable alkali and acid extraction contained virtually pure mycelial chitosan.

\subsection{Characterization of Mycelial Chitosan}

Isolated mycelial chitosan obtained by submerged fermentation by evaluating some of the physical properties including glucosamine content, Fourier-transform infrared (FTIR) spectroscopy, degree of deacetylation (DD), viscosity and molecular weight (MW).

\subsubsection{Determination of Glucosamine Content}

Determination of glucosamine content of mycelial chitosan was based on colorimetric measurement. Chitosan samples after extraction were hydrolyzed with $2 \mathrm{M}$ hydrochloric acid at $110^{\circ} \mathrm{C}$ for $2 \mathrm{~h}$ and the liberated D-glucosamine was deaminated with nitrous acid to yield 2,5-anhydromannose which react with 3-methyl-2benzothiazolinone hydrazone hydrochloride (MBTH) to produce intense blue-colored complex measured at 650 $\mathrm{nm}[20]$.

\subsubsection{Infra Red Spectroscopy}

The structure of extracted mycelial chitosan was confirmed by infra red spectroscopy using KBr pellet method in FTIR (Perkin Elmer Model 1600 Series, MA, USA). In FTIR spectra were recorded in the middle infrared ( $4000 \mathrm{~cm}^{-1}$ to $400 \mathrm{~cm}^{-1}$ ) with a resolution of $4 \mathrm{~cm}^{-1}$ in the absorbance mode for 16 scans at room temperature. The mycelial chitosan samples were prepared by grinding the dry mycelial chitosan powder with powdered $\mathrm{KBr}$, in the ratio of 1:5 (sample:KBr) and then compressed to form $\mathrm{KBr}$ pellet and subjected to FTIR analysis [21].

\subsubsection{Degree of Deacetylation}

The degree of deacetylation (DD) was determined using the concept of baseline method [22]. The IR spectrum 
recording procedure is same as described above. According to the IR spectrum, the DD was calculated by measuring the absorbance ratio of $\mathrm{A}_{1655}$ and $\mathrm{A}_{3450}$ [23]. The amide I band at $1655 \mathrm{~cm}^{-1}$ and the hydroxyl group absorption band at $3450 \mathrm{~cm}^{-1}$ were used as internal reference. An equation proposed by Baxter et al. for determination of degree of deacetylation is as follow:

$$
\text { Degree of deacetylation }=100-\left[\left(\mathrm{A}_{1655} / \mathrm{A}_{3450}\right) \times 115\right]
$$

\subsubsection{Determination of Viscosity and Molecular Weight}

Viscosity of mycelial chitosan was determined with an Ubbelohde-type capillary viscometer [24]. Chitosan solution $(1 \% \mathrm{v} / \mathrm{v})$ was prepared in $2 \%(\mathrm{v} / \mathrm{v})$ acetic acid, stirred for $4 \mathrm{~h}$ and filtered to remove insoluble materials. After that, the solution was allowed to stand to remove air bubbles. Measurements were made in triplicate on each sample at $25^{\circ} \mathrm{C}$. Values were reported in $\mathrm{dL} / \mathrm{g}$. The running times of the solution and solvent were recorded as seconds (sec) and used to calculate intrinsic viscosity $\left[\eta_{\text {in }}\right]$. The reduced viscosity $\left(\eta_{\text {red }}\right)$, which is specific vis$\operatorname{cosity}\left(\eta_{\mathrm{sp}}\right) /$ concentration $(\mathrm{C})$, as tabulated, $\left(\eta_{\mathrm{red}}=\eta_{\mathrm{sp}} / \mathrm{C}\right)$ where $\left(\eta_{\mathrm{sp}}=\eta_{\text {relative }}-1\right)$, and

$$
\eta_{\text {relative }}=\frac{\text { viscosity of solution }}{\text { viscosity of solvent }}
$$

Relative viscosity $\left(\eta_{\text {rel }}\right)=$ specific viscosity $\left(\eta_{\mathrm{sp}}\right)=\eta_{\text {rel }}-1$

Reduced viscosity $\left(\eta_{\text {red }}\right)$ vs. concentration of chitosan solution (g/dl, \%) were plotted on a graph. The intrinsic viscosity $\left(\left[\eta_{\mathrm{in}}\right], \mathrm{dl} / \mathrm{g}\right)$ was obtained by extrapolating reduced viscosity vs. concentration data to zero concentration.

Using this value of the intrinsic viscosity ([ $\left.\left.\eta_{\text {in }}\right], \mathrm{dl} / \mathrm{g}\right)$ average molecular weight of mycelial chitosan (Mw) was determined. The viscosity-average molecular weight of mycelial chitosan solutions were calculated using the Mark Houwink equation which provides the relationship between intrinsic viscosity and molecular weight [25].

$$
\left.[\eta]=K M^{a} \text { (Mark Houwink equation }\right)
$$

where, " $K$ " and " $a$ " are constants for given solute-solvent system and temperature.

\section{Results and Discussions}

A process of screening is necessary to determine the most influential factors affecting the cultivation process. In order to obtain the suitability of fermentation conditions the effect of various strains, incubation period, $\mathrm{pH}$, temperature and various carbon and nitrogen sources on biomass and mycelial chitosan yield, was investigated.

\subsection{Screening of Different Fungal Strains}

Screening of fungal strains for mycelial chitosan producers are presented in Figure 1. Maintaining the fermentation parameters same, DCW of the strains ranges from $3.6 \mathrm{~g} / \mathrm{L}$ (R. oryzae NCIM 1009) to $6.8 \mathrm{gm} / \mathrm{L}$ (A. butleri NCIM 977). In our screening among five fungal strains, we found that A. butleri NCIM 977 gave maximum production of mycelial chitosan $(401 \mathrm{mg} / \mathrm{L})$ followed by C. echinulata NCIM 691 (372 mg/L) and $R$. oryaze NCIM 1009 (274 mg/L). According to Bartnicki-Garcia [7] Zygomycetes species, contains chitosan as natural components of their cell wall. Nwe et al. [11] suggested that chitosan biosynthesis starts with production of chitin with the conversion of glucose into N-acetylglucosamine-1-phosphate, which reacts with UTP to form UDP$\mathrm{N}$-acetylglucosamine in a reaction catalyzed by glucosamine-6-phosphate synthase. Subsequently, the enzyme chitin synthase transfer the sugar dimer of N-acetylglucosamine moiety into the growing chitin polymer chain. Furthermore in Zygomycetes, deacetylation of the growing chitin chain occurs through the action of the enzyme chitin deacetylase which results in formation of mycelial chitosan. From the present experiment, it was found that $A$. butleri NCIM 977 was the most suitable fungal strain since it produced highest mycelial chitosan and therefore used for further optimization study.

\subsection{Screening of Physical Parameters and Nutrients by One-Factor-at-a-Time Method}

In order to determine the optimum batch time for mycelial chitosan production, fermentation process was car- 
ried out in $200 \mathrm{ml}$ of sterile production media at $30^{\circ} \mathrm{C} \pm 2^{\circ} \mathrm{C}$ on a rotary shaker at $160 \mathrm{rpm}$ for different time level ranging from $12 \mathrm{~h}$ to $96 \mathrm{~h}$. It was observed that $72 \mathrm{~h}$ time period resulted into maximum mycelial chitosan production of $585.33 \mathrm{mg} / \mathrm{L}$ with DCW $7.6 \mathrm{~g} / \mathrm{L}$ (Figure 2). Further increase in fermentation time observed low productivity and biomass concentration which may be due to physiological changes in the fungal cell wall [19]. Rane and Hoover [26] reported that decrease in mycelial chitosan yield is due to its degradation by chitosanase activity. Chitosan is produced in the fungal cell wall by deacetylating its precursor, nascent chitin [12]. During the exponential phase, the ratio of free chitosan molecules is relatively high, due to the active growth. Once the

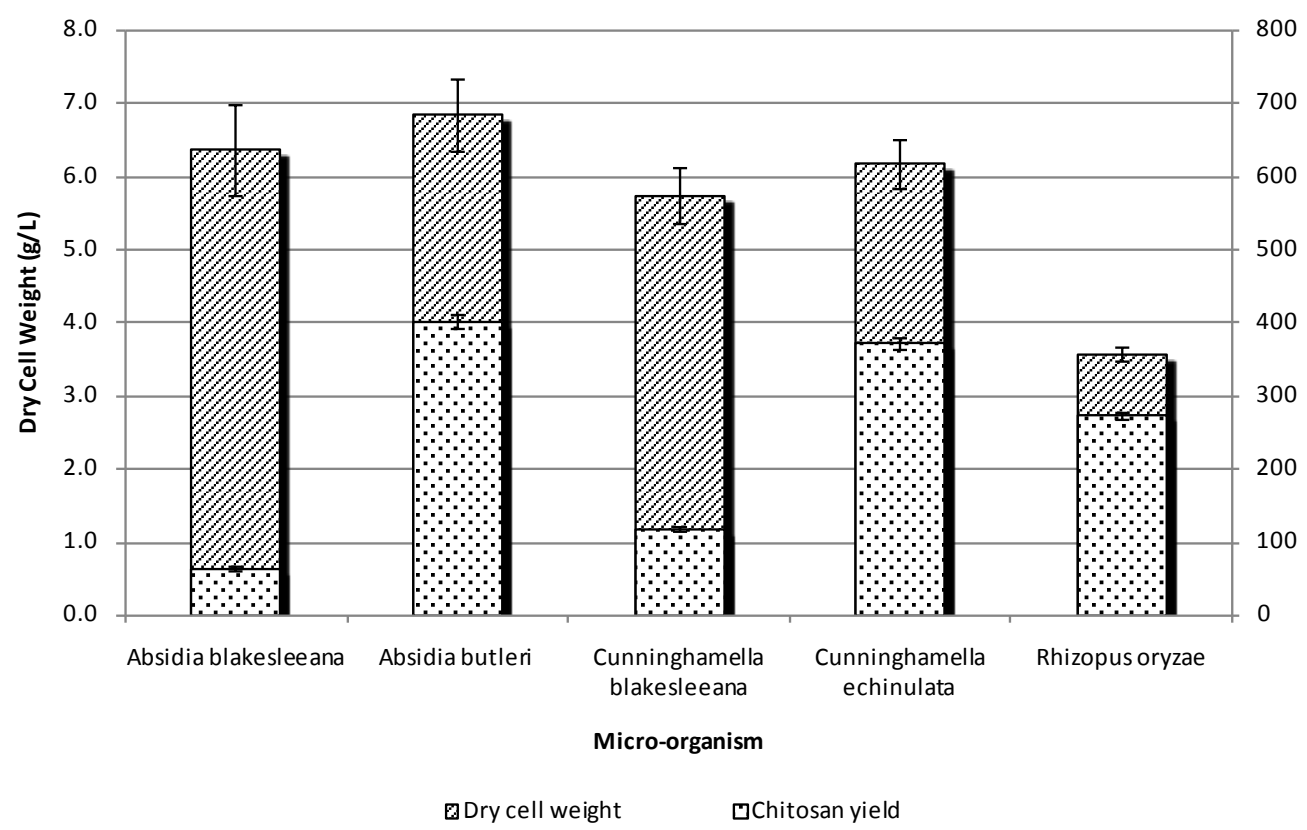

Figure 1. Screening of fungal strains for mycelial chitosan production by A. butleri NCIM 977.

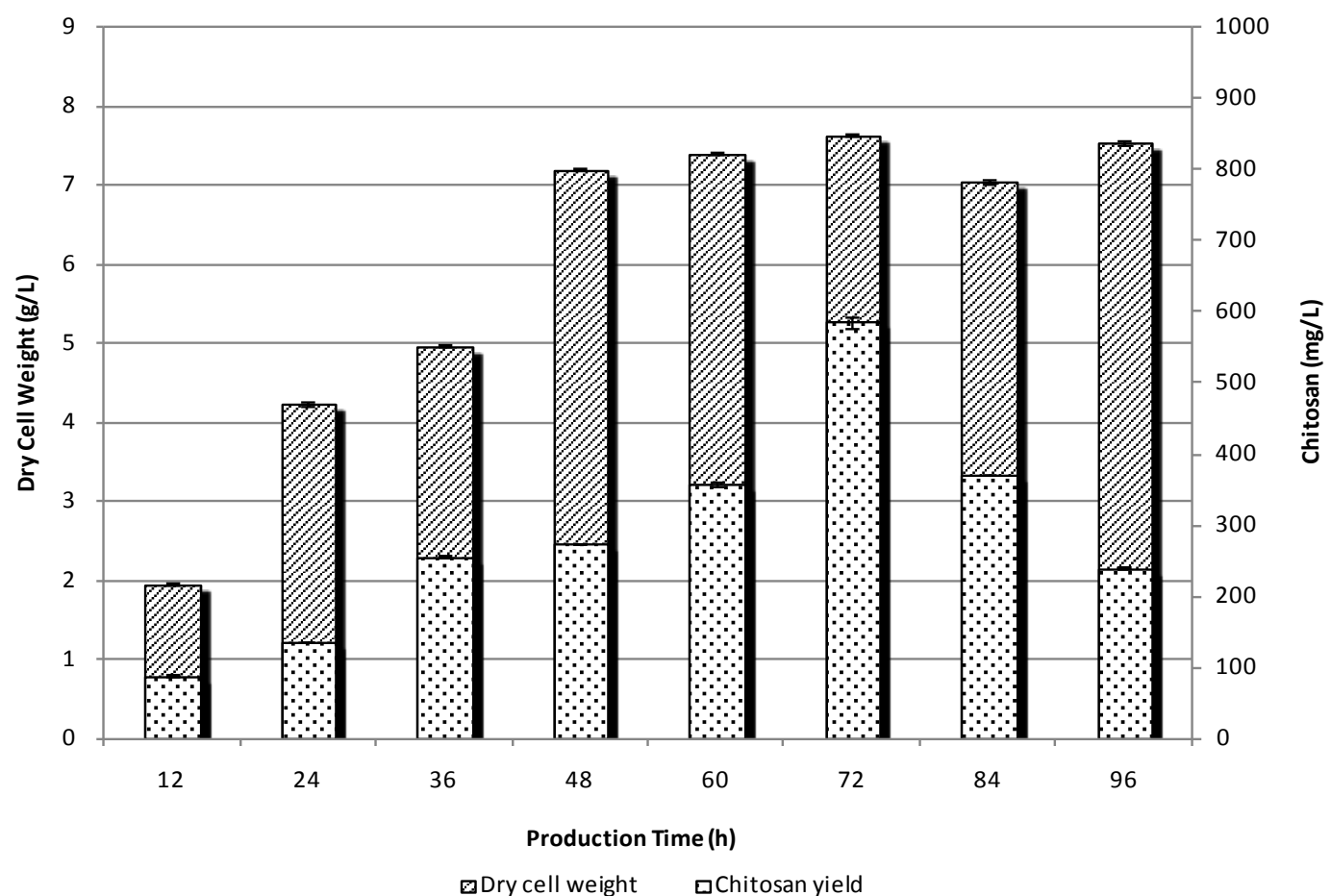

Figure 2. Effect of fermentation batch time on mycelial chitosan production by A. butleri NCIM 977. 
culture enters the stationary growth phase, more of the chitosan is anchored to the cell wall of the Zygomycetes by binding to chitin and other polysaccharides and extraction becomes more difficult [7]. Therefore, although the fungal biomass was increased during the stationary growth phase, less chitosan is obtained while maximum mycelial chitosan yields at the late exponential phase [12].

\subsection{Effect of Different Initial pH Values on Production of Mycelial Chitosan Yield}

The $\mathrm{pH}$ of the medium always influences the physiology of a microorganism by affecting nutrient desirability, enzyme activity, oxidative-reductive reactions and most importantly cell membrane morphology. Among the various initial $\mathrm{pH}$ range studied (3 - 6), an initial $\mathrm{pH} 5.5$ supported the maximum production of mycelial chitosan $(669.16 \mathrm{mg} / \mathrm{L})$ as well as biomass (Figure 3). The results were in agreement with the studies reported by Synowiecki and Ali-Khateeb [18] for Mucor rouxii while Yokoi et al. [27] for Gongronella species and Muzzarelli et al. [28] for Absidia coerulea for mycelail chitosan production. This may be due to the fact that the $\mathrm{pH}$ ranging from 4.5 to 5.5, favors the production of enzyme chitin deacetylase, which convert chitin to chitosan in fungal cell wall [13].

\subsection{Effect of Different Effect of Temperature on Production of Mycelial Chitosan Yield}

Temperature influences the metabolic activities and microbial growth which affects the production. In order to find out the effect of temperature on mycelial chitosan production, fermentation was carried out at different temperatures ranging from $20^{\circ} \mathrm{C}$ to $35^{\circ} \mathrm{C}$. The yield increases from $20^{\circ} \mathrm{C}$ till $30^{\circ} \mathrm{C}$ and further decreased at $35^{\circ} \mathrm{C}$ (Figure 4). A maximum mycelial chitosan production of $667.16 \mathrm{mg} / \mathrm{L}$ with highest biomass production (8.4 g/L) was observed at $30^{\circ} \mathrm{C}$.

\subsection{Effect of Carbon Sources on Production of Mycelial Chitosan Yield}

During microbial fermentations, the carbon source not only acts as a major constituent for building of cellular material, but also as an important energy source. All carbon sources with $2 \%(w / v)$ concentration showed different effects on mycelial chitosan production (Figure 5). The fungal strain A. butleri NCIM 977 grown on the medium supplemented with fructose, sucrose, galactose resulted in increase biomass production however glucose as a sole carbon source supported the highest biomass as well as mycelial chitosan production as compared to other carbon sources. Among all carbon sources glucose employed showed maximum mycelial chitosan production $(683.16 \mathrm{mg} / \mathrm{L})$ with DCW of $8.3 \mathrm{~g} / \mathrm{L}$, followed by galactose $(383 \mathrm{mg} / \mathrm{L})$, fructose $(343.33 \mathrm{mg} / \mathrm{L})$, and sucrose $(291.5 \mathrm{mg} / \mathrm{L})$. It may be due to the fact that glucose can be easily assimilated in the metabolic pathway for biosynthesis.

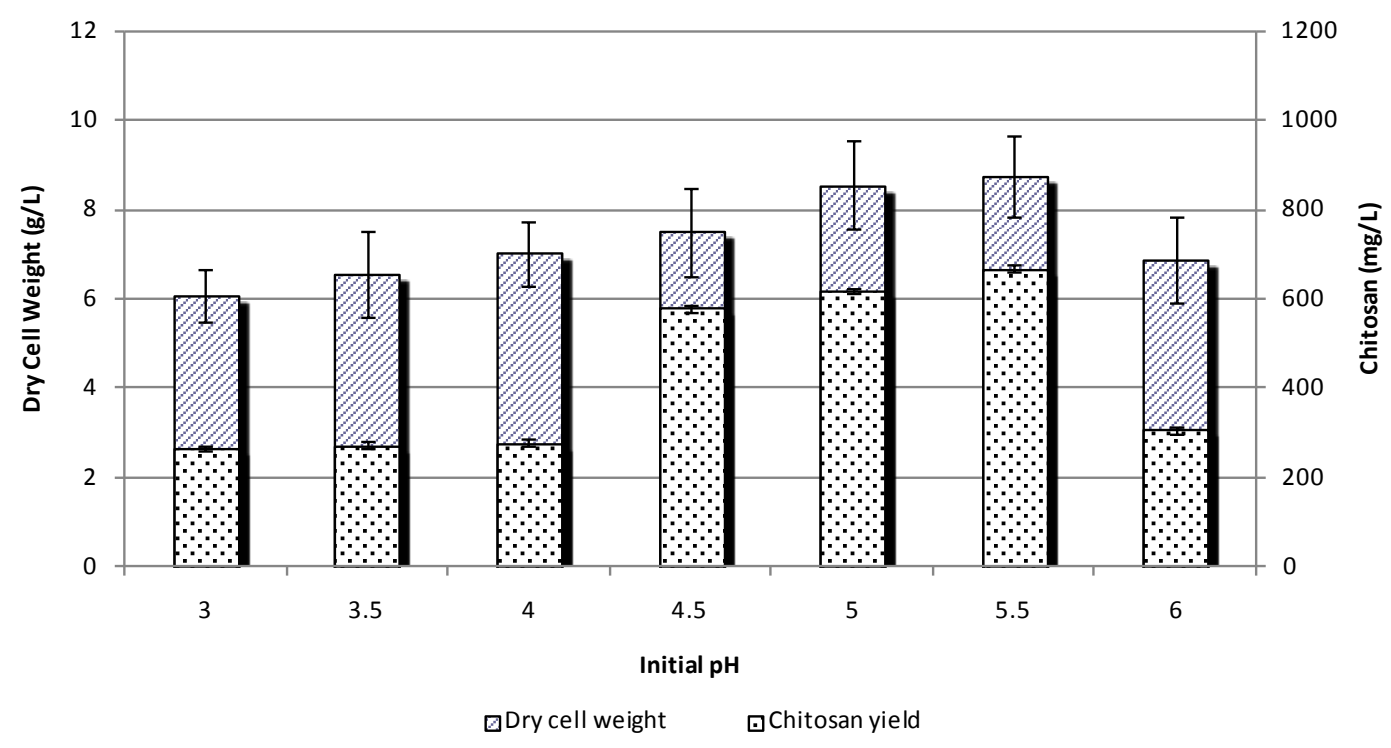

Figure 3. Effect of initial pH on mycelial chitosan production by A. butleri NCIM 977. 


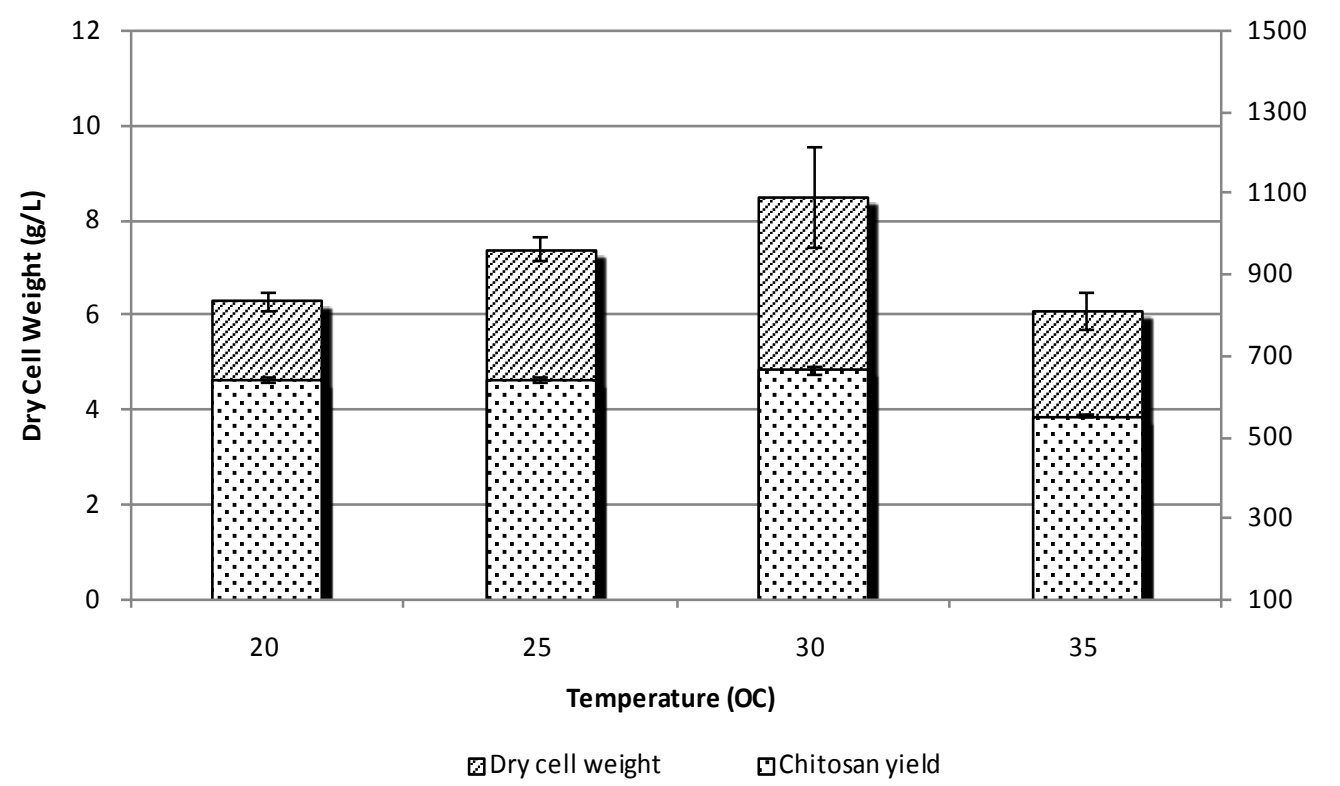

Figure 4. Effect of temperature on mycelial chitosan production by A. butleri NCIM 977.

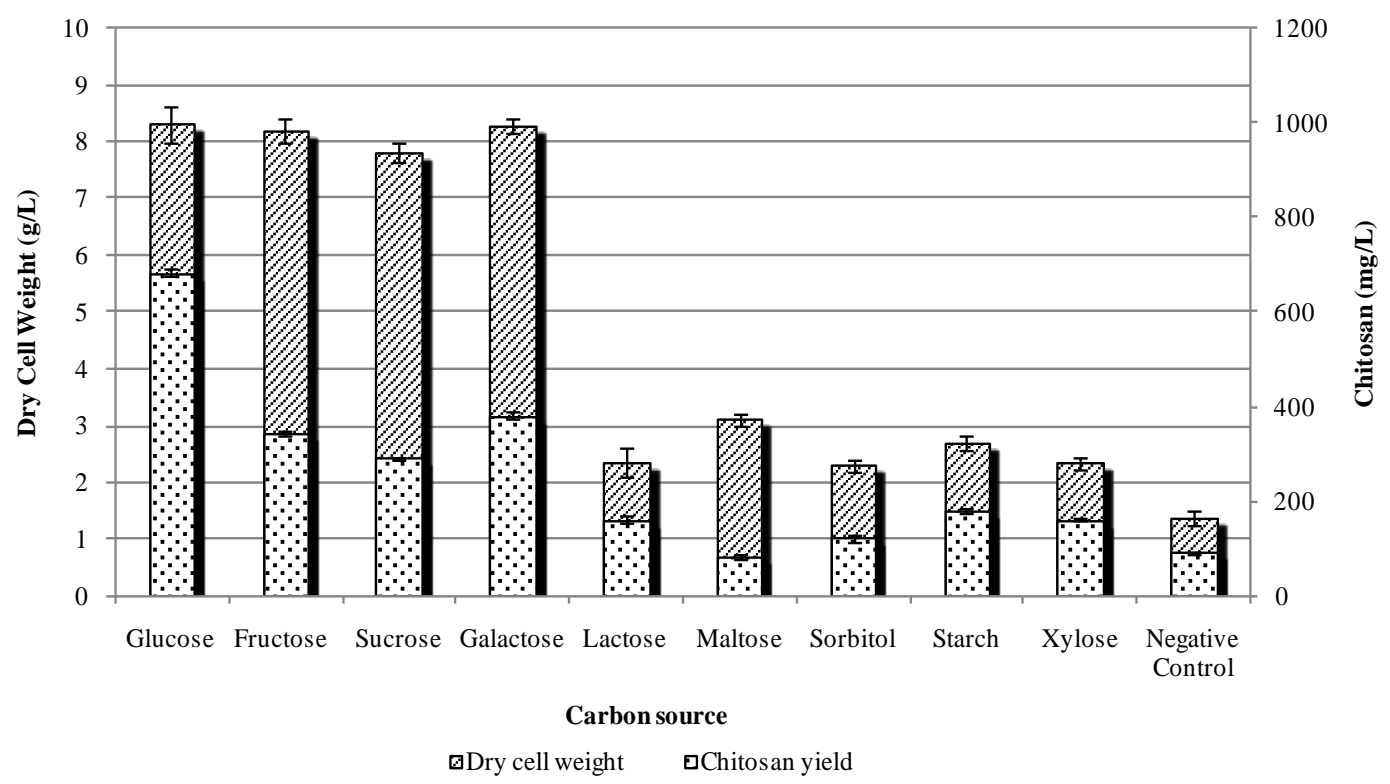

Figure 5. Effect of carbon sources on mycelial chitosan production by A. butleri NCIM 977.

\subsection{Effect of Nitrogen on Production of Mycelial Chitosan Yield}

The nitrogen source is a critical factor which needs to be optimized for mycelial chitosan production. Chitosan is a nitrogen containing biopolymer, which is deacetylated form chitin. Fungi require an inorganic or organic nitrogen source as nutrient to synthesize the chitin and chitosan for their cell wall. Hence the nitrogen source is one of the important factors for the production of chitosan by fungi [29]. Among the organic and inorganic nitrogen sources, organic nitrogen source exhibited a prominent effect on mycelial chitosan production (Figure 6 and Figure 7). Among the organic nitrogen sources studied soyabean meal produced the highest DCW of 11.13 $\mathrm{g} / \mathrm{L}$ followed by beef extract $(7.44 \mathrm{~g} / \mathrm{L})$ and yeast extract $(7.06 \mathrm{~g} / \mathrm{L})$. However, tryptone supported the maximum production of mycelial chitosan $(570.33 \mathrm{mg} / \mathrm{L})$ with DCW of $6.78 \mathrm{~g} / \mathrm{L}$. In the absence of nitrogen source, chitosan yield was found to be drastically decreased, hence it can be concluded that that nitrogen source is significant parameter in the fermentative production of mycelial chitosan. 


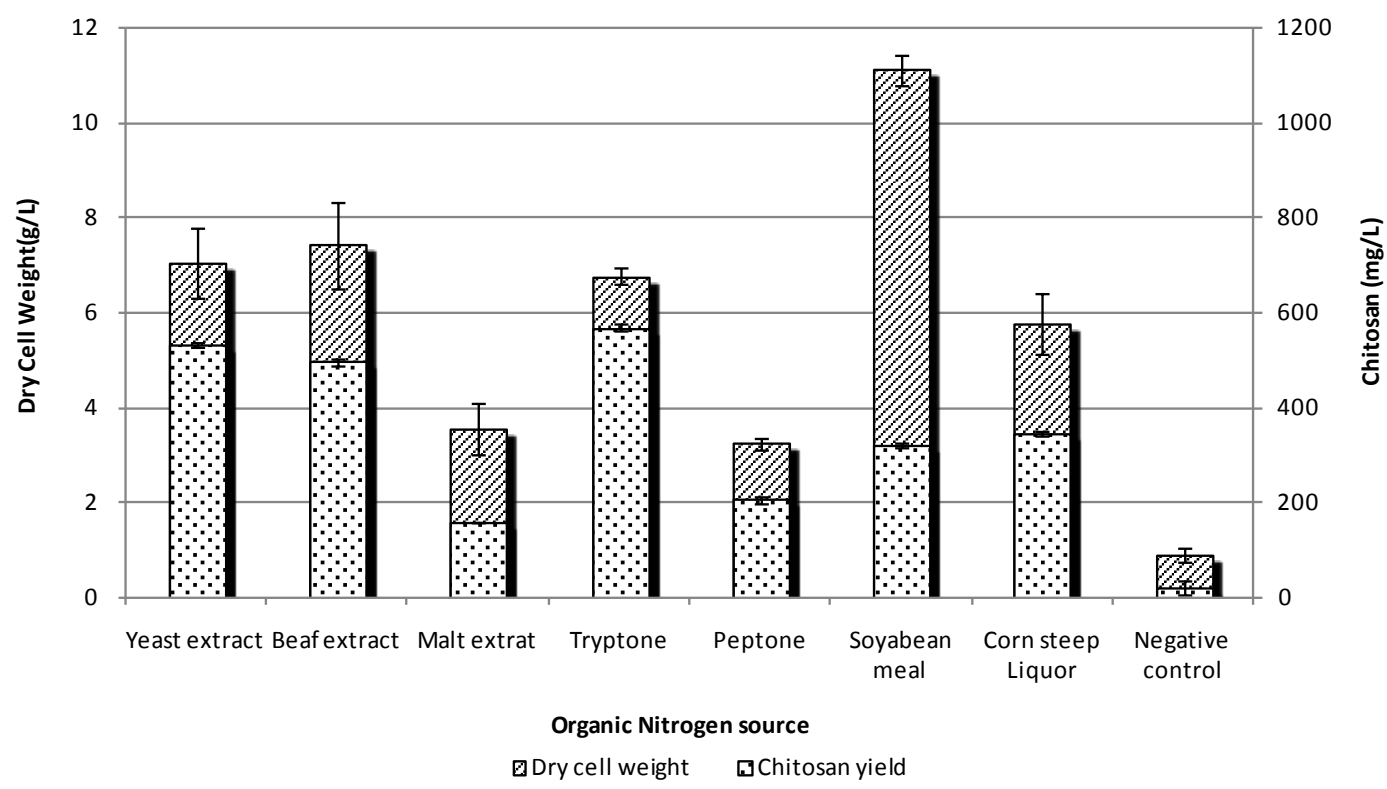

Figure 6. Effect of organic nitrogen sources on mycelial chitosan production by A. butleri NCIM 977.

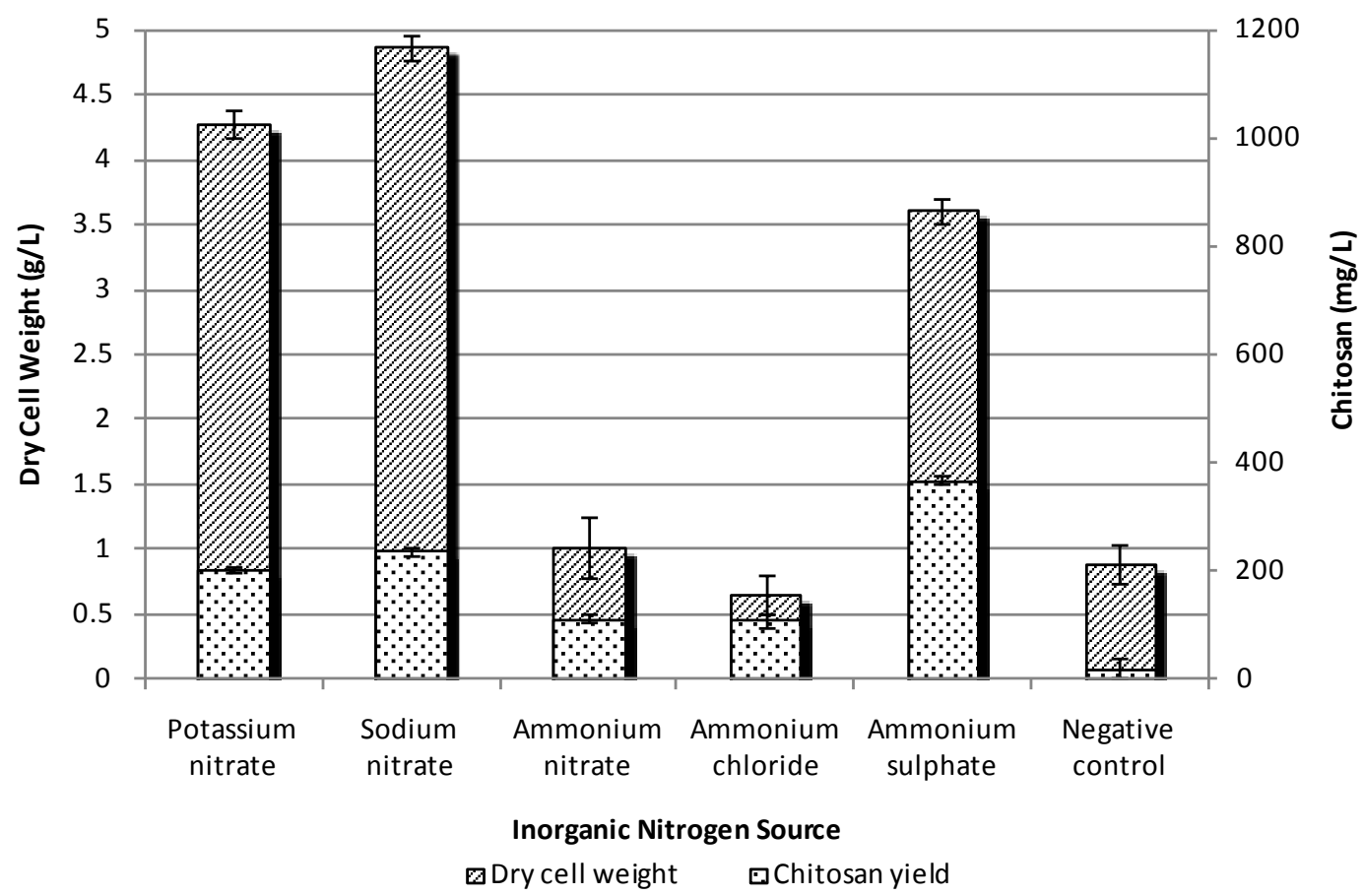

Figure 7. Effect of inorganic nitrogen sources on mycelial chitosan production by A. butleri NCIM 977.

\subsection{Optimization of Culture Conditions by Box-Behnken Design}

In this study, according to Box-Behnken design, all 17 designed experiments were conducted with different combinations of three independent parameters (glucose, tryptone and yeast extract) at three different levels, low $(-1)$, medium (0) and, high (+1) to study the combined effects of these factors towards yield of mycelial chitosan. The variables and their coded levels used for the study are shown in Table 1. Box-Behnken design matrix of independent variables in coded units along with experimental and predicted values for mycelial chitosan production is shown in Table 2. The results were analyzed by multiple regression analysis. Maximum yield of mycelial chitosan ( $1 \mathrm{~g}$ per litre of fermentation media) was recorded under the experimental conditions having media 
Table 2. Box-Behnken design matrix with experimental and predicted values of chitosan production by A. butleri NCIM 977.

\begin{tabular}{|c|c|c|c|c|c|}
\hline \multirow{2}{*}{ Run No. } & \multicolumn{3}{|c|}{ Media concentration \% (w/v) } & \multicolumn{2}{|c|}{ Chitosan (g/L) } \\
\hline & Glucose (A) & Tryptone (B) & Yeast extract (C) & Actual $^{\mathrm{a}}$ & Predicted \\
\hline 1 & 2.50 & 1.10 & 1.60 & 0.21 & 0.18 \\
\hline 2 & 1.50 & 1.60 & 1.10 & 1 & 0.99 \\
\hline 3 & 2.00 & 1.60 & 1.60 & 0.83 & 0.84 \\
\hline 4 & 1.50 & 1.60 & 2.10 & 0.66 & 0.64 \\
\hline 5 & 2.50 & 2.10 & 1.60 & 0.29 & 0.29 \\
\hline 6 & 2.00 & 1.60 & 1.60 & 0.86 & 0.84 \\
\hline 7 & 2.00 & 1.60 & 1.60 & 0.89 & 0.84 \\
\hline 8 & 2.00 & 2.10 & 1.10 & 0.65 & 0.63 \\
\hline 9 & 2.00 & 2.10 & 2.10 & 0.48 & 0.48 \\
\hline 10 & 2.50 & 1.60 & 2.10 & 0.44 & 0.45 \\
\hline 11 & 2.00 & 1.10 & 2.10 & 0.32 & 0.34 \\
\hline 12 & 2.00 & 1.60 & 1.60 & 0.84 & 0.84 \\
\hline 13 & 1.50 & 1.10 & 1.60 & 0.54 & 0.54 \\
\hline 14 & 2.50 & 1.60 & 1.10 & 0.52 & 0.54 \\
\hline 15 & 2.00 & 1.10 & 1.10 & 0.64 & 0.64 \\
\hline 16 & 2.00 & 1.60 & 1.60 & 0.78 & 0.84 \\
\hline 17 & 1.50 & 2.10 & 1.60 & 0.54 & 0.57 \\
\hline
\end{tabular}

${ }^{\mathrm{a}}$ Values are mean \pm SD of three determinations.

concentrations of glucose $1.5 \%(\mathrm{w} / \mathrm{v})$, tryptone $1.6 \%(\mathrm{w} / \mathrm{v})$, and yeast extract $1.1 \%(\mathrm{w} / \mathrm{v})$. Consequently, the following second order polynomial equation for mycelial chitosan production was regressed and expressed in term of coded factors. It represents yield of mycelial chitosan $\left(Y_{C Y}\right)$ as a function of concentration of glucose (A), tryptone (B) and yeast extract (C).

$$
\begin{aligned}
Y_{C Y}= & 0.84-0.16 \mathrm{~A}+0.031 \mathrm{~B}-0.11 \mathrm{C}-0.16 \mathrm{~A}^{2}-0.29 \mathrm{~B}^{2}-0.029 \mathrm{C}^{2} \\
& +0.020 \mathrm{AB}+0.065 \mathrm{AC}+0.037 \mathrm{BC}
\end{aligned}
$$

In order to determine whether or not the quadratic model is significant, it is necessary to conduct analysis of variance (ANOVA). ANOVA for response surface quadratic model is presented in Table 3 . The p-values were used as a tool to check the significance of each coefficient, which, in turn are necessary to understand the pattern of the mutual interactions between the test variables. The lower p-values are the more significant and effective in process parameters [30]. Here, the p-value of the model was smaller than 0.0001 , which indicated that the model was suitable for use in this experiment. The lack of fit test, measures the failure of the model to represent experimental data in the experimental domain at point which are not included in regression analysis [31]. The p-value of "lack of fit" was 0.6031 ( $p>0.01$ ), indicated that "lack of fit" was insignificant relative to the pure error and the model equation was adequate to predict yield of mycelial chitosan under any sets of combination of variables. The regression coefficients and the corresponding p-values were presented in Table 4. From the p-values of each model term, it could be concluded that two linear coefficients (A, C), two quadratic coefficients $\left(\mathrm{A}^{2}, \mathrm{~B}^{2}\right)$ and one cross-product coefficients (AC) were significant. It implies that three parameters are very critical for the production of mycelial chitosan and there was strong interaction between concentrations of glucose and yeast extract. The statistical significance of the polynomial equation was carried by F-test. The model F- 
Table 3. Analysis of variance (ANOVA) for the fitted quadratic polynomial model of mycelail chitosan productiona from the results of Box-Behnken experimental design.

\begin{tabular}{cccccc}
\hline Source & Sum of squares & $\mathrm{df}^{\mathrm{a}}$ & Mean square & F-value & Prob $>\mathrm{F}$ \\
Model & 0.83 & 9 & 0.092 & 64.20 & $<0.0001^{*}$ \\
Lack of fit & $3.425 \mathrm{E}-003$ & 3 & $1.142 \mathrm{E}-003$ & 0.60 & $0.6031^{* *}$ \\
Residual & 0.010 & 7 & $1.432 \mathrm{E}-003$ & & \\
Pure error & $6.600 \mathrm{E}-003$ & 4 & $1.650 \mathrm{E}-003$ & & \\
Correlation total & 0.84 & 16 & & \\
\hline
\end{tabular}

${ }^{\mathrm{a} D e g r e e ~ o f ~ f r e e d o m ; ~}{ }^{*}$ Significant; ${ }^{* *}$ Not significant.

Table 4. Regression coefficients and their significance of the quadratic model of mycelial chitosan production by A. butleri NCIM 977.

\begin{tabular}{cccccc}
\hline Model term & Coefficient of estimate & $\mathrm{df}^{\mathrm{a}}$ & Standard error & F-value & Prob $>\mathrm{F}$ \\
\hline Intercept & 0.84 & 1 & 0.017 & - & $<0.0001$ \\
A & -0.16 & 1 & 0.013 & 143.00 & 0.0522 \\
B & 0.031 & 1 & 0.013 & 5.46 & 72.28 \\
C & -0.11 & 1 & 0.013 & 71.78 & $<0.0001$ \\
A $^{2}$ & -0.16 & 1 & 0.018 & 245.13 & $<0.0001$ \\
B $^{2}$ & -0.29 & 1 & 0.018 & 2.43 & 0.1630 \\
C $^{2}$ & -0.029 & 1 & 0.018 & 1.12 & 0.3256 \\
AB & 0.020 & 1 & 0.019 & 11.80 & 0.0109 \\
AC & 0.065 & 1 & 0.019 & 3.93 & 0.0879 \\
BC & 0.037 & 1 & 0.019 & \\
\hline
\end{tabular}

A-Glucose; B-Tryptone; C—Yeast extract; ${ }^{\mathrm{a}}$ Degree of freedom; ${ }^{*}$ Significant; ${ }^{* *}$ Not significant.

value of 64.20 ( $\mathrm{p}<0.0001)$ implies the model is significant and is calculated as ratio of mean square regression and mean square residual. The goodness of fit of the model was checked by coefficient of determination $\left(\mathrm{R}^{2}\right)$ and adjusted coefficient of determination (adjusted $\mathrm{R}^{2}$ ). The $\mathrm{R}^{2}$ value varies from 0 to 1.0 and close to $1.0 \mathrm{im}$ plies better accuracy of the model. But in certain cases higher $\mathrm{R}^{2}$ value may be resulted in presence of large number of insignificant variables in the model and thereby predicts poor response. So the term adjusted $\mathrm{R}^{2}$ was introduced which corrects $\mathrm{R}^{2}$ value accordingly to the sample size and number of terms in model. Ideally adjusted $R^{2}$ should be close to $R^{2}$ value. Larger difference between $R^{2}$ and adjusted $R^{2}$ gives warning that model content too many insignificant terms [32]. The high $\mathrm{R}^{2}$ value (0.9880) indicates, good correlation between experimental and predicted values and $98.80 \%$ of the variability in the response could be explained by the model. The $\mathrm{R}^{2}$ of 0.9880 is in reasonable agreement with the adjusted $\mathrm{R}^{2}$ of 0.9726 confirming the validity of the model. "Adequate Precision" measures the signal to noise ratio and its value can be predicted by statistical analysis. A ratio greater than 4 is desirable [32]. In the present study, a ratio of 27.907 indicates an adequate signal. This explains that the model can be used to navigate the design space. The coefficient of variation (CV) is the ratio of the standard error of estimate to the mean value of the observed response, expressed as a percentage. Usually, the higher the value of $\mathrm{CV}$, the lower is the reliability of experiment while low $\mathrm{CV}$ value predicts accuracy and reliability of the experiments conducted [33]. Here CV value was found to be 6.13 indicates a greater degree of precision. This is also evident from the parity plot (Figure 8), obtained by plotting observed and predicted yield of mycelial chitosan and it suggests satisfactory correlation between experimental and predicted value, as the data points were confined close to the digonal line, showing that the prediction of experimental data is quite satisfactory. 
Perturbation graph shows the effect of each of the independent variables on response while keeping other variables at their respective zero level. From Figure 9 it is revealed that tryptone concentration (B) was most critical factor followed by glucose concentration (A) whereas yeast concentration (C) is least influential factor for the production of mycelial chitosan.

Accordingly, 3-D response surface plot were generated for the pairwise combination of two independent variables where remaining variables are fixed at their respective zero level and described by the regression model which illustrate the interactive effect of this independent variables on the response variable and also determine optimum level of each variable [34].

Figure 10(a) represents the effects of glucose concentration, tryptone concentration and their reciprocal interactions on yield of mycelial chitosan at constant yeast extract concentration of $1.6 \%(w / v)$. At the designed

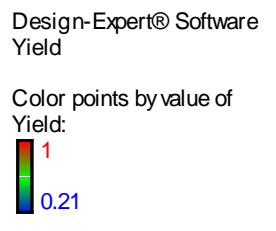

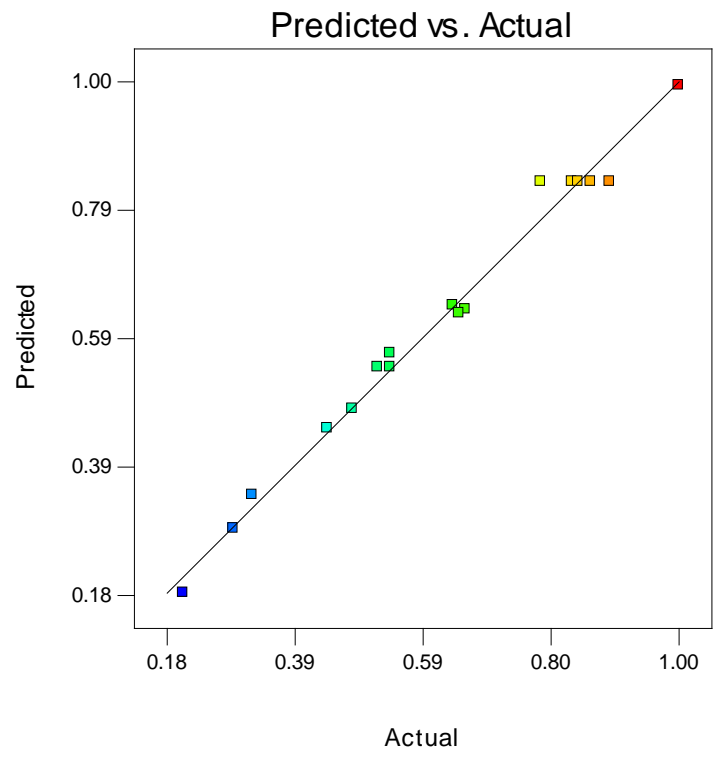

Figure 8. Parity plot for actual and model predicted values for mycelial chitosan production.

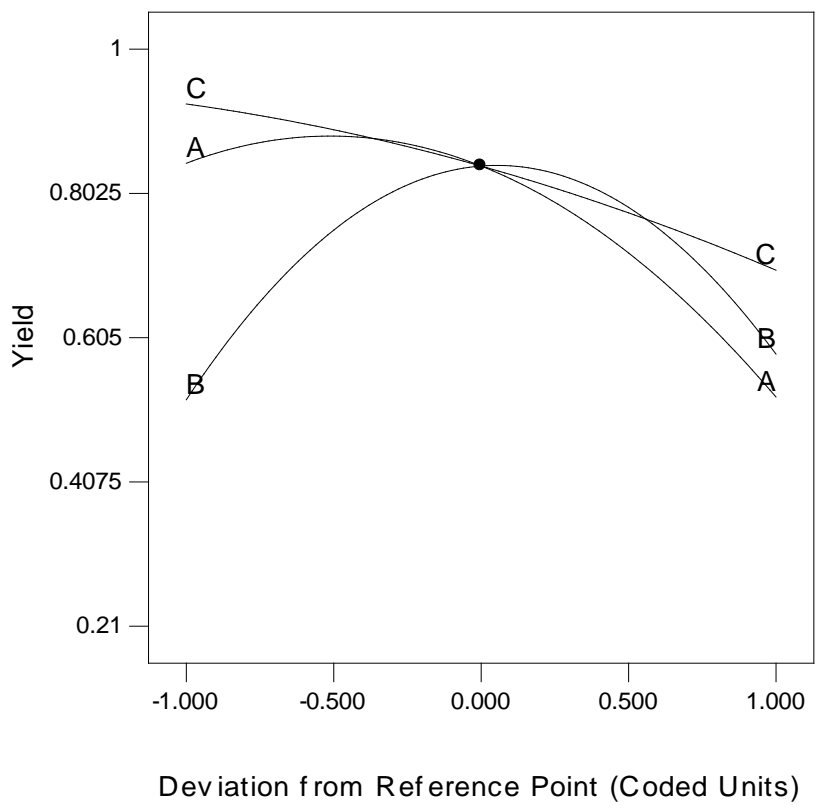

Figure 9. Perturbation graph showing the effect of each in dependent variable on mycelial chitosan production while keeping other variables at their respective zero level. 
Design-Expert $\circledast$ Software
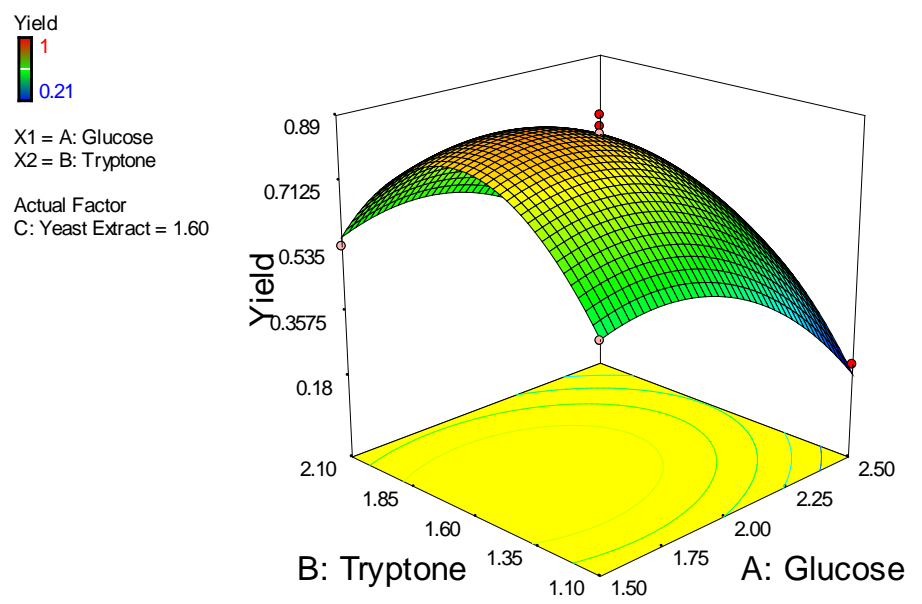

(a)

Design-Expert $\circledast$ Software

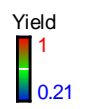

$X 1=A$ : Glucose $\mathrm{X} 2=\mathrm{C}$ : Yeast Extract

Actual Factor

B: Tryptone $=1.60$

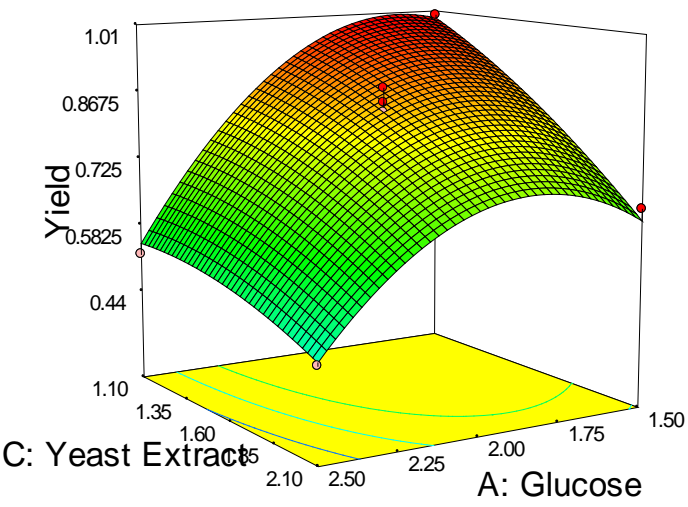

(b)

Design-Expert $₫$ Software

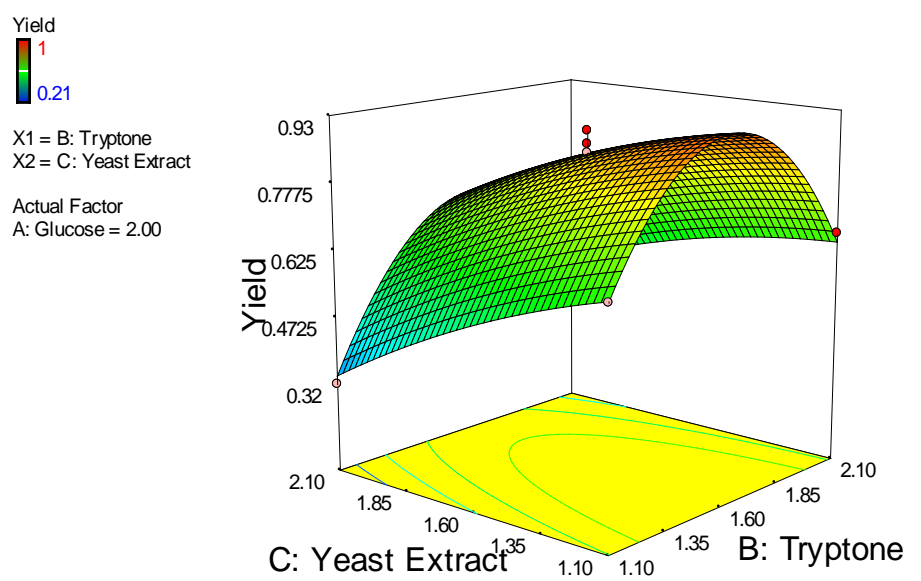

(c)

Figure 10. (a) Response surface plots showing relative effect of two variables glucose and tryptone; (b) Response surface plots showing relative effect of two variables glucose and yeast extract; (c) Response surface plots showing relative effect of two variables tryptone and yeast extract. 
range of glucose concentration from $1.5 \%(\mathrm{w} / \mathrm{v})$ to $2.5 \%(\mathrm{w} / \mathrm{v})$, the amplification of mycelial chitosan yield resulted in a linear increase in tryptone concentration, and then reduced. It can be inferred that yield of mycelial chitosan was markedly affected by the combination of glucose concentration and tryptone concentration. An increase of tryptone concentration increased the mycelial chitosan yield at a constant glucose concentration within a tryptone concentration of $1.6 \%(\mathrm{w} / \mathrm{v})$. The appropriate maximal mycelial chitosan yield was determined at a glucose concentration of $1.5 \%(\mathrm{w} / \mathrm{v})$. Figure 10(b) shows the effects of glucose concentration, yeast extract concentration and their reciprocal interactions on mycelial chitosan yield at a tryptone concentration of $1.6 \%$ $(\mathrm{w} / \mathrm{v})$. At the designed range of glucose concentration from $1.5 \%(\mathrm{w} / \mathrm{v})$ to $2.5 \%(\mathrm{w} / \mathrm{v})$, the yield of mycelial chitosan increased with decreasing concentration of yeast extract. At low concentration of yeast extract, the yield of mycelial chitosan was found to be maximum. It could be seen from Figure 10(b) that at high concentrations of both glucose and yeast extract the yield of mycelial chitosan was minimum while the optimum concentrations of glucose and yeast extract for maximum mycelial chitosan production was around $1.5 \%(\mathrm{w} / \mathrm{v})$ and $1.1 \%(\mathrm{w} / \mathrm{v})$ respectively. The effect of concentrations of tryptone and yeast extract on the yield of mycelial chitosan at a glucose concentration of 2\% (w/v) is provided in Figure 10(c). At first, an increase in mycelial chitosan yield was observed with the increasing of yeast extract and tryptone concentration. But the trend was reversed when the concentrations of glucose and tryptone reached a certain value. It could be seen from Figure 10(c) that yield of mycelial chitosan was affected significantly by tryptone concentration.

In order to verify the predicted results, an experiment was performed using the optimized nutrient levels. The optimum conditions for these selected parameters were predicted using desirability function criteria available in design expert software. The maximum predicted mycelial chitosan production could be achieved with glucose concentration of $1.58 \% \mathrm{w} / \mathrm{v}(\mathrm{A})$, Tryptone concentration of $1.61 \% \mathrm{w} / \mathrm{v}(\mathrm{B})$, and yeast concentration of $1.11 \%$ $\mathrm{w} / \mathrm{v}(\mathrm{C})$. Under these conditions experiments were carried out in triplicate. The mean value of the yield of mycelial chitosan was $1.002 \mathrm{mg} / \mathrm{L}$, which agreed with the predicted value $(1.0012 \mathrm{mg} / \mathrm{L})$ well. As a result, the models developed were considered to be accurate and reliable for predicting the production of mycelial chitosan from A. butleri NCIM 977.

\subsection{Characterizations}

\subsubsection{Determination of Glucosamine Content}

Chitosan are linear polysaccharides consisting of N-acetyl-D-glucosamine and D-glucosamine units present in different ratios in the polymers. The glucosamine content in chitosan isolated from fungal source A. butleri NCIM 977 was determined to be $80.68 \%$, a little more than the report of Synowieki and Al-khateeb [18]. The relatively high content of glucosamine showed that the product contained mainly aminosugars and its purity was up to $80.68 \%$.

\subsubsection{Infra Red Spectroscopy}

IR spectroscopy has been reported as a relatively quick, simple technique and commonly used for qualitative and quantitative evaluations of chitin and chitosan characteristics, mainly their functional groups, the degree of acetylation/deacetylation and impurities [23]. The FTIR spectrum of mycelial chitosan from A. butleri NCIM 977 obtained from submerged fermentation was compared with standard chitosan are shown in Figure 11. Several bands have been proposed as internal reference bands of chitosan: the $\mathrm{OH}$ stretching band at $3450 \mathrm{~cm}^{-1}$; the C-H stretching bands within $2870-2880 \mathrm{~cm}^{-1}$; the skeletal vibrations involving the C-O-C stretching band at $1030-1070 \mathrm{~cm}^{-1}$; the $-\mathrm{CH}_{2}$ bending centered at $1420 \mathrm{~cm}^{-1}$; the anti-symmetric stretching of the C-O-C bridge around $1160 \mathrm{~cm}^{-1}$; $1315-1320 \mathrm{~cm}^{-1}$ (amide III band); $1620-1630 \mathrm{~cm}^{-1}$ (-NH bending of $\mathrm{NH}_{2}$ ); and $890-900$ $\mathrm{cm}^{-1}$ (C-O-C bridge as well as glucosidic linkage) [25]. In present study, our results were also similar to those reported by Kasaai [25] and Khan [22] and similar to that of mycelial chitosan obtained from M. rouxii [18]. The most significant parts of these spectra are those showing the amide bonds at approximately 1655 and $1313 \mathrm{~cm}^{-1}$. Other functional group include hydroxyl stretching band at $3427 \mathrm{~cm}^{-1}$, amide I band at 1655, primary amine band at $1638-1561 \mathrm{~cm}^{-1}$ amide II band at $1561 \mathrm{~cm}^{-1}$ and amide III band at $1320 \mathrm{~cm}^{-1}$. The band at $897 \mathrm{~cm}^{-1}$ was referenced as glycosidic linkage of $\beta$-anomer. These absorption bands preliminary ascertained the product to be chitosan.

\subsubsection{Degree of Deacetylation}

IR spectroscopic method was commonly used for determination of DD value of mycelial chitosan. It was initially 


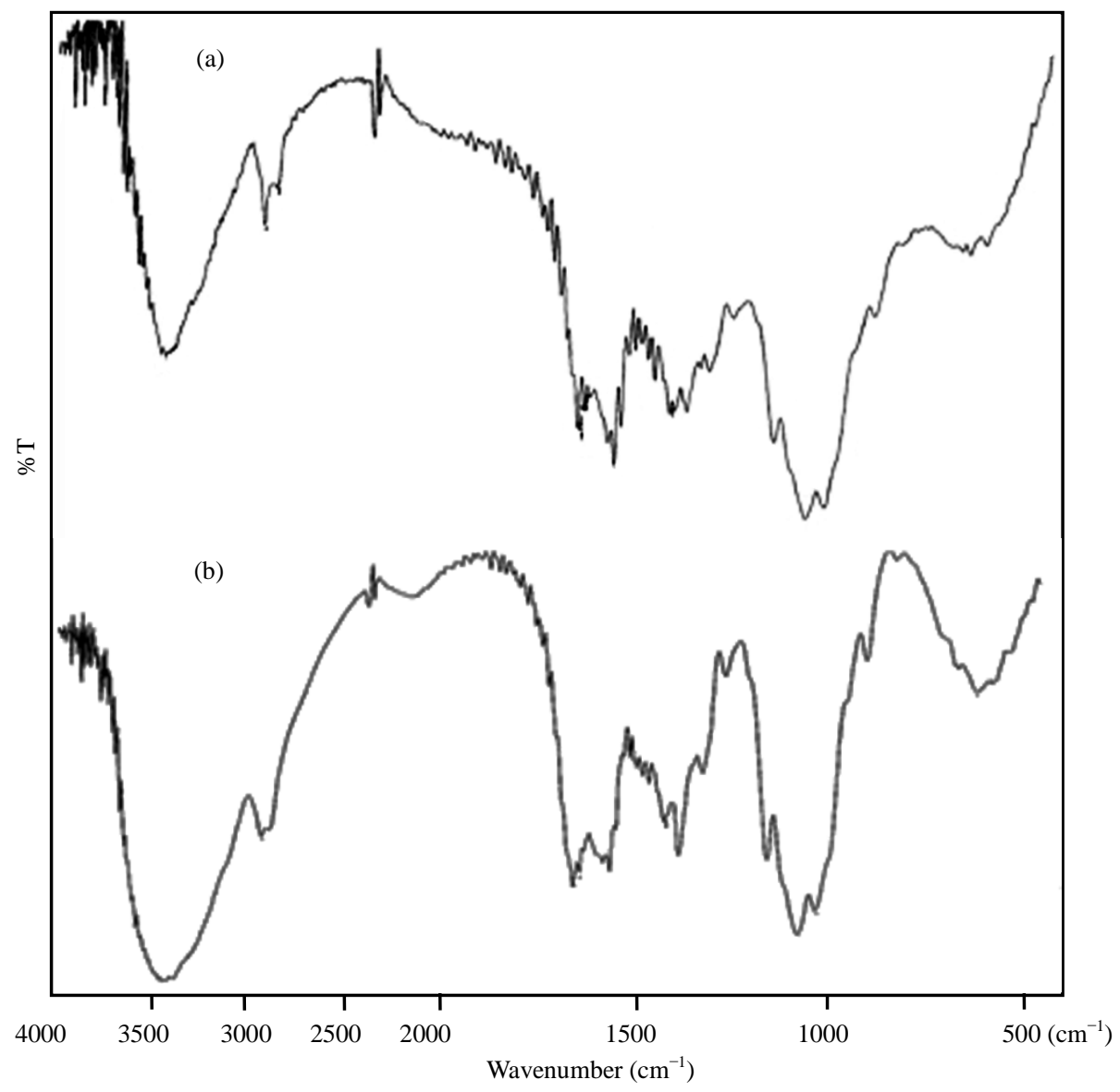

Figure 11. FTIR spectra of (a) standard chitosan and (b) mycelial chitosan obtained from A. butleri NCIM 977cultivated on optimized formula.

proposed by Moore and Roberts. It has a number of advantages like relatively fast method and does not require dissolution of the chitosan sample in an aqueous solvent. IR spectroscopy is primarily a solid-state method utilizing the concept of baseline for DD calculation. The baseline proposed by Baxter et al. [23] was modified from the method reported by Domszy and Roberts [22]. In the present study, the DD value of mycelial chitosan obtained from submerged fermentation of A. butleri NCIM 977 was determined to be $79.89 \%$. In present study DD value of mycelial chitosan was found to be slightly lower than the reported values of DD of chitosan from other fungi [13] [14] [35].

\subsubsection{Determination of Viscosity and Molecular Weight}

The viscosity of mycelial chitosan obtained from the submerged fermentation of A. butleri NCIM 977 was 73.22 $\mathrm{dl} / \mathrm{g}$. The molecular weight of mycelial chitosan was depends and vary upon substrate, medium supplementation and fermentation mode. The viscosity average molecular weight of mycelial chitosan was calculated from Mark Houwink equation. In present study the molecular weight (MW) of mycelial chitosan was found to be $8.07 \times 10^{4}$ Da and was lower compared to commercial chitosan. Previous research has reported the MW to be between $3 \times$ $10^{4} \mathrm{Da}-1.4 \times 10^{5} \mathrm{Da}$ [13] [36]. As compared to high molecular weight chitosan, low molecular weight chitosan exhibit better antimicrobial activity especially for bacterial pathogens [37] and extensively used for pharmaceutical products [38].

\section{Conclusion}

In conclusion, the maximum yield of mycelial chitosan was obtained from A. Butleri NCIM 977 under the cultivation condition of $\mathrm{pH} 5.5$ and temperature $30^{\circ} \mathrm{C}$ with production batch time of $72 \mathrm{hrs}$. Subsequently, the cul- 
ture media supplemented with glucose, yeast extract and tryptone produced the highest yield of mycelial chitosan. An increase in the yield of mycelial chitosan was dependent on the supplementation and interaction of nitrogen source with other media components. The results indicated that the choice of media and nitrogen supplements are critical factors in obtaining high yield of mycelial chitosan. The media composition also affected the glucosamine content, degree of deacetylation, viscosity and molecular weight of the mycelial chitosan and was found to be $80.68 \%, 79.89 \%, 73.22 \mathrm{ml} / \mathrm{g}$ and $8.07 \times 10^{4}$ Da respectively. Interestingly, low molecular weight chitosan with desirable physico-chemical properties would be achieved under submerged fermentation and could be potentially applied to the food, cosmetic, chemical and pharmaceutical industries. In summary, fermentative production of mycelial chitosan can be a good alternative to lessen environmental pollution of strong alkali from traditional chitosan production and provides a new, simple and green technology for production of low-molecular-weight chitosan.

\section{References}

[1] No, H.K., Meyers, S.P. and Lee, K.S. (1989) Isolation and Characterization of Chitin from Crawfish Shell Waste. Journal of Agricultural and Food Chemistry, 37, 575-579. http://dx.doi.org/10.1021/jf00087a001

[2] Shahidi, F., Arachch, J.K.V. and Jeon, Y.J. (1999) Food Applications of Chitin and Chitosans. Trends in Food Science Technology, 10, 37-51. http://dx.doi.org/10.1016/S0924-2244(99)00017-5

[3] Kumar, M.N.V. (2000) A Review of Chitin and Chitosan Applications. Reactive and Functional Polymers, 46, 1-27. http://dx.doi.org/10.1016/S1381-5148(00)00038-9

[4] Dodane, V. and Vilivalam, V.D. (1998) Pharmaceutical Applications of Chitosan. Pharmaceutical Science Technology Today, 1, 246-253. http://dx.doi.org/10.1016/S1461-5347(98)00059-5

[5] Knorr, D. (1991) Recovery and Utilization of Chitin and Chitosan in Food Processing Waste Management. Food Technology, 45, 114-122.

[6] Wang, W., Du, Y., Qiu, Y., Wang, X., Hu, Y., Yang, J., Cai, J. and Kennedy, J.F. (2008) A New Green Technology for Direct Production of Low Molecular Weight Chitosan. Carbohydrate Polymers, 74, 127-132. http://dx.doi.org/10.1016/j.carbpol.2008.01.025

[7] Bartniki-Garcia, S. (1968) Cell Wall Chemistry, Morphogenesis and Taxonomy of Fungi. Annual Review of Microbiology, 22, 87-108. http://dx.doi.org/10.1146/annurev.mi.22.100168.000511

[8] Kleekayai, T. and Suntornsuk, W. (2011) Production and Characterization of Chitosan Obtained from Rhizopus oryzae Grown on Potato Chip Processing Waste. World Journal of Microbiology and Biotechnology, 27, 1145-1154. http://dx.doi.org/10.1007/s11274-010-0561-x

[9] Cardoso, A., Lins, C.I.M., Santos, E.R., Freitas Silva, M.C. and Campos-Takaki, G.M. (2012) Microbial Enhance of Chitosan Production by Rhizopus arrhizus Using Agroindustrial Substrates. Molecules, 17, 4904-4914. http://dx.doi.org/10.3390/molecules17054904

[10] Santos, E.R., Freitas Silva, M.C., Souza, P.M., Silva, A.C., Paiva, S.C., Albuquerque, C.D.C., Nascimento, A.E., Okada, K. and Campos-Takaki, G.M. (2013) Enhancement of Cunninghamella elegans ucp/wfcc 0542 Biomass and Chitosan with Amino Acid Supply. Molecules, 18, 10095-10107. http://dx.doi.org/10.3390/molecules180910095

[11] New, N., Stevens, W.F., Tokura, S. and Tamura, H. (2008) Characterization of Chitosan and Chitosan-Glucan Complex Extracted from Cell Wall of Fungus Gongronella butleri USDB 0201 by Enzymatic Method. Enzyme and Microbial Technology, 42, 242-251. http://dx.doi.org/10.1016/j.enzmictec.2007.10.001

[12] Tan, S.C., Tan, T.K., Wong, S.M. and Khor, E. (1996) The Chitosan Yield of Zygomycetes at Their Optimum Harvesting Time. Carbohydrate Polymers, 30, 239-242. http://dx.doi.org/10.1016/S0144-8617(96)00052-5

[13] Arcidiacono, S. and Kaplan, D.L. (1992) Molecular Weight Distribution of Chitosan Isolated from Mucor rouxii under Different Culture and Processing Conditions. Biotechnology and Bioengineering, 39, 281-286. http://dx.doi.org/10.1002/bit.260390305

[14] Crestini, C., Kovac, B. and Giovannozzi-Sermanni, G. (1996) Production and Isolation of Chitosan by Submerged and Solid-State Fermentation from Lentinus edodes. Biotechnology and Bioengineering, 50, 207-210. http://dx.doi.org/10.1002/bit.260500202

[15] Jaworska, M.M. and Konieczna, E. (2001) The Influence of Supplemental Components in Nutrient Medium on Chitosan Formation by Fungus Absidia orchidis. Applied Microbiology and Biotechnology, 56, 220-224. http://dx.doi.org/10.1007/s002530000591

[16] New, N. and Stevens, W.F. (2002) Chitosan Isolation from the Chitosan-Glucan Complex of Fungal Cell Wall Using Amylolytic Enzymes. Biotechnology Letters, 24, 1461-1464. http://dx.doi.org/10.1023/A:1019898715518 
[17] Box, G.E.P. and Behnken, D.W. (1960) Some New Three Level Designs for the Study of Quantitative Variables. Technometrics, 2, 455-475. http://dx.doi.org/10.1080/00401706.1960.10489912

[18] Synowiecki, J. and Ali-Khateeb, N.A.A.Q. (1997) Mycelia of Mucor rouxii as a Source of Chitin and Chitosan. Food Chemistry, 60, 605-610. http://dx.doi.org/10.1016/S0308-8146(97)00039-3

[19] McGahren, W.J., Perkinson, G.A., Growich, J.A., Leese, R.A. and Ellestad, G.A. (1984) Chitosan by Fermentation. Process Biochemistry, 19, 88-90.

[20] Tsuji, A., Kinoshita, T. and Hoshino, M. (1969) Analytical Chemical Studies on Amino Sugars. II Determination of Hexosamines Using 3-Methyl-2-Benzothiazolone Hydrazone Hydrochloride. Chemical and Pharmaceutical Bulletin, 17, 1505-1510. http://dx.doi.org/10.1248/cpb.17.1505

[21] Kumirska, J., Czerwicka, M., Kaczyński, Z., Bychowska, A., Brzozowski, K., Thöming, J. and Stepnowski, P. (2010) Application of Spectroscopic Methods for Structural Analysis of Chitin and Chitosan. Marine Drugs, 8, 1567-1636. http://dx.doi.org/10.3390/md8051567

[22] Khan, T.A., Peh, K.K. and Ch’ng, H.S. (2002) Reporting Degree of Deacetylation Values of Chitosan: The Influence of Analytical Methods. Journal of Pharmacy and Pharmaceutical Sciences, 5, 205-212.

[23] Baxter, A., Dillon, M., Taylor, K.D.A. and Roberts, G.A.F. (1992) Improved Method for i.r. Determination of the Degree of N-Acetylation of Chitosan. International Journal of Biological Macromolecules, 14, 166-169. http://dx.doi.org/10.1016/S0141-8130(05)80007-8

[24] Mao, S., Shuai, X., Unger, F., Simona, M., Bi, D. and Kissel, T. (2004) The Depolymerization of Chitosan: Effects on Physicochemical and Biological Properties. International Journal of Pharmaceutics, 281, 45-54. http://dx.doi.org/10.1016/j.ijpharm.2004.05.019

[25] Kasaai, M.R., Arul, J. and Charlet, G. (2000) Intrinsic Viscosity-Molecular Weight Relationship for Chitosan. Journal of Polymer Science Part B: Polymer Physics, 38, 2591-2598. http://dx.doi.org/10.1002/1099-0488(20001001)38:19<2591::AID-POLB110>3.0.CO;2-6

[26] Rane, K.D. and Hoover, D.G. (1993) Production of Chitosan by Fungi. Food Biotechnology, 7, 11-33. http://dx.doi.org/10.1080/08905439309549843

[27] Yokoi, H., Aratake, T., Nishio, S., Hirose, J., Hayashi, S. and Takasaki, Y. (1998) Chitosan Production from Shochu Distillery Waste Water by Funguses. Journal of Fermentation and Bioengineering, 85, 246-249. http://dx.doi.org/10.1016/S0922-338X(97)86777-3

[28] Muzzarelli, R.A.A., Ilari, P., Tarsi, R., Dubini, B. and Xia, W.S. (1994) Chitosan from Absidia coerulea. Carbohydrate Polymers, 25, 45-50. http://dx.doi.org/10.1016/0144-8617(94)90161-9

[29] New, N. and Stevens, W.F. (2004) Effect of Urea on Fungal Chitosan Production in Solid Substrate Fermentation. Process Biochemistry, 39, 1639-1642. http://dx.doi.org/10.1016/S0032-9592(03)00301-7

[30] Murthy, M.S.R.C., Swaminathan, T., Rakshit, S.K. and Kosugi, Y. (2000) Statistical Optimization of Lipase Catalyzed Hydrolysis of Methyloleate by Response Surface Methodology. Bioprocess Engineering, 22, 35-39. http://dx.doi.org/10.1007/PL00009097

[31] Sharma, P., Singh, L. and Dilbaghi, N. (2009) Optimization of Process Variables for Decolorization of Disperses Yellow 211 by Bacillus subtilis Using Box-Beknken Design. Journal of Hazardous Materials, 169, 1024-1029. http://dx.doi.org/10.1016/j.jhazmat.2008.08.104

[32] Haaland, P.D. (1989) Experimental Design in Biotechnology. Marcel Dekker, New York.

[33] Sen, R. and Swaminathan, T. (2004) Response Surface Modeling and Optimization to Elucidate and Analyze the Effects of Inoculums Age and Size on Surfactin Production. Biochemical Engineering Journal, 21, 141-148. http://dx.doi.org/10.1016/j.bej.2004.06.006

[34] Yetilmezsoy, K., Demirel, S. and Vanderbei, R.J. (2009) Response Surface Modeling of Pb(II) Removal from Aqueous Solution by Pistacia vera L.: Box-Behnken Experimental Design. Journal of Hazardous Materials, 171, 551-562. http://dx.doi.org/10.1016/j.jhazmat.2009.06.035

[35] Miyoshi, H., Shimura, K., Watanabe, K. and Onodera, K. (1992) Characterization of Some Fungal Chitosans. Bioscience, Biotechnology, and Biochemistry, 56, 1901-1905. http://dx.doi.org/10.1271/bbb.56.1901

[36] Pochanavanich, P. and Suntornsuk, W. (2002) Fungal Chitosan Production and Its Characterization. Letters in Applied Microbiology, 35, 17-21. http://dx.doi.org/10.1046/j.1472-765X.2002.01118.x

[37] No, H.K., Meyers, S.P., Prinyawiwatkul, W. and Xu, Z. (2007) Applications of Chitosan for Improvement of Quality and Shelf Life of Foods: A Review. Journal of Food Science, 72, 87-100. http://dx.doi.org/10.1111/j.1750-3841.2007.00383.x

[38] Li, Q., Dunn, E.T., Grandmaison, E.W. and Goosen, M.F.A. (1992) Applications and Properties of Chitosan. Journal of Bioactive and Compatible Polymers, 7, 370-397. http://dx.doi.org/10.1177/088391159200700406 
Scientific Research Publishing (SCIRP) is one of the largest Open Access journal publishers. It is currently publishing more than 200 open access, online, peer-reviewed journals covering a wide range of academic disciplines. SCIRP serves the worldwide academic communities and contributes to the progress and application of science with its publication.

Other selected journals from SCIRP are listed as below. Submit your manuscript to us via either submit@scirp.org or Online Submission Portal.
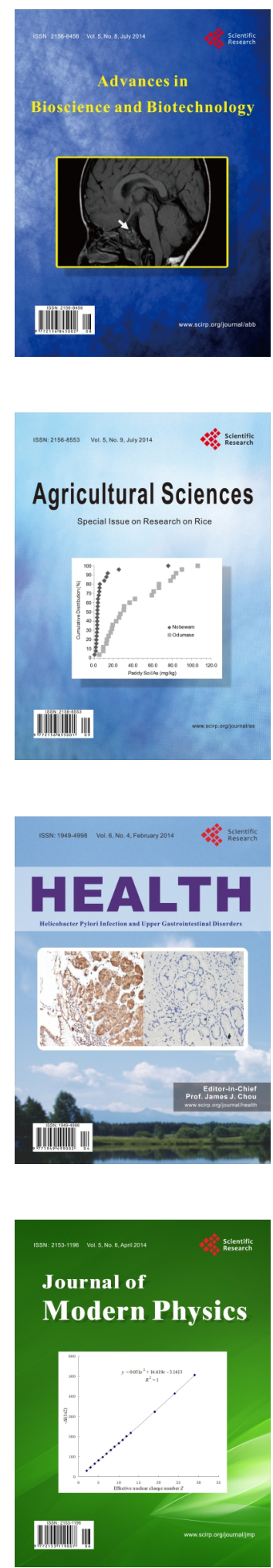
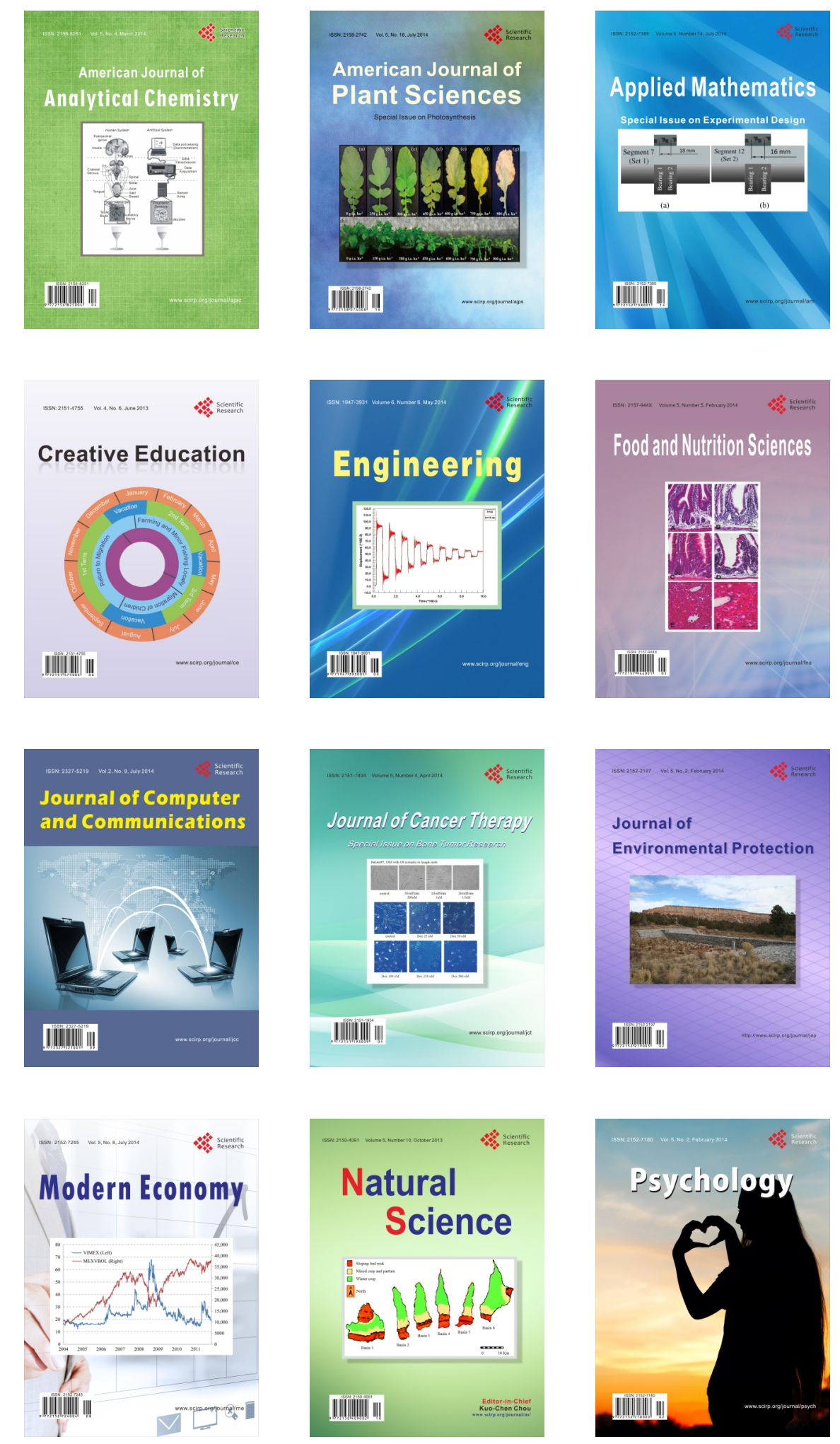